\title{
Arqueología e investigación documental: las defensas pre- abaluartadas de Alacant (España)
}

Archaeology and documentary research: the first bastioned fortifications of Alacant (Spain)

\section{Màrius Bevià i Garcia a, Juan Antonio Mira Rico ${ }^{\text {b }}$, Jaime Manuel Giner Martínez ${ }^{\text {c, }}$ José Ramón Ortega Pérez ${ }^{d}$}

a Architect, Sant Joan d'Alacant, Spain, mariusbg@gmail.com

${ }^{\mathrm{b}}$ Universitat Oberta de Catalunya / ICOMOS-ICOFORT, Castalla, Spain, mirarico@ hotmail.com

${ }^{\mathrm{c}}$ Architect, Alicante, Spain, jaimeginer@arquired.es

d Arpa Patrimonio, Sant Vicent del Raspeig, Spain, arpaoscu@ gmail.com

\begin{abstract}
In the Courts of the Crown of Aragon held in Monzón (Huesca, 1528) it was raised the need to organise the coast defence of the Kingdom of Valencia through a series of fortification works and the creation and maintenance of militias in order to avoid the attacks and incursions of the Turks and the Berber corsairs. In Alacant (1533), under the auspice of the Duke of Calabria, viceroy of the Kingdom of Valencia, and the design of Joan de Cervelló, noble, military and engineer of King Carlos I and with great experience in artillery and fortification of cities, three bastions were built taking advantage of the medieval walls: Sant Francesc, Sant Bertomeu and Sant Sebastià. These improvement works on the walls continued with the rise of two more towers that protected the gate (Puerta del Mar or Montserrat). The bastions had a circular plan and an escarp elevation up to their half and vertical until the crowning, besides a low armed parapet. They were demolished because of the urban renovations that Alacant experienced during the nineteenth century. However, the historical planimetry, engraving images and photographs, as well as the archaeological excavations carried out in them allow to know their morphology and materials, which are explained in this paper.
\end{abstract}

Keywords: Alacant, archaeology, first bastioned architecture, documentary research.

\section{Introducción}

Para repeler los ataques de los corsarios berberiscos procedentes del norte de África (García, 1980, p. 47), en las Cortes de la Corona de Aragón reunidas en Monzón (1528), se planteó la necesidad de organizar la defensa de la costa del Reino de Valencia, así como un sistema de financiación, para cubrir los gastos de las obras y de las milicias urbanas, que corrió a cargo de la Generalitat Valenciana y de las plazas, ciudades y villas objeto de la intervención, caso de, entre otras, Alacant, Benidorm, Cullera, Peníscola y Vila Joiosa. Así pues, se cargaron censales sobre algunas vi- llas y ciudades de realengo por valor de 23000 libras que fueron puestas a disposición del contador Álvaro de Loaces, el capitán Aldana y el ingeniero Joan de Cervelló, que formaron parte de los ejércitos expedicionarios, en la península Itálica, de Fernando el Católico y Carlos I, respectivamente (Bevià i Garcia, Camarero Casas, 1985, pp. $65,66)$. Este último, por ejemplo, contaba con una gran experiencia en artillería y fortificaciones. Todos ellos intervinieron en la fortificación de las villas de realengo de Alacant, Benidorm, además de Cullera, y Peníscola, durante las déca- 
das de los años treinta y cincuenta del siglo XVI (Pardo, 2006). Un proceso que, también, tuvo su eco, en lugares señoriales, caso de Castalla (Bevià i Garcia, et al., 2017).

Poniendo el foco de atención en la ciudad de Alacant, dicho momento histórico ya ha sido estudiado, por lo tanto, no se repetirá en este trabajo (González, 2012). Así pues, el objetivo de este trabajo es, a partir de las fuentes documentales existentes -descripciones parciales, grabados con diverso grado de realidad, planimetría histórica y una fotografía de 1858-, la información obtenida en las diferentes actuaciones arqueológicas realizadas (Borrego Colomer, Rosser Limiñana, 2014; López Seguí, Torregrosa Giménez, 2015; Soler López, et al., 2002); y la comparación con diversos paralelos -como los torreones de Salses (Francia) o Vila Joiosa-; proceder a la reconstrucción gráfica de los cubos artillados edificados en la vieja muralla del Medievo. Aquí conviene resaltar que, como bien señaló J. Ivars Pérez (2015, pp. 254, 260), en su trabajo sobre la ciudad y el Castell de Dénia, el elevado número de castillos medievales existentes no podía ser sustituido por fortalezas de nueva planta. Por ello, a finales del siglo XV y durante la primera mitad del siglo $\mathrm{XVI}$, se impuso la construcción de piezas arquitectónicas pre-abaluartadas adaptadas a la artillería, aunque manteniendo tipologías tardomedievales.

En Alacant (Fig. 1), sobre las murallas medievales, en 1533, comenzaron a edificarse tres torreones: Sant Francesc, protegiendo la puerta de l'Horta; Sant Bertomeu, junto al portal d'Elx; y Sant Sebastià, en el portal Nou. En los dos últimos, se colocaron dos lápidas en donde se confirmaba la autoría del ingeniero Cervelló de dichas construcciones. Las diversas obras de mejoras de las murallas continuaron con el levantamiento de los dos cubos de la Nostra Senyora de Montserrat, que protegían la puerta del Mar. Por último, se edificó la torre de l'Ampolla (Fig. 2). Dicha torre, la única que sobrevivió a la expansión urbanística de Alicante durante el siglo XIX, es de la misma tipología que las anteriores, a pesar de su tardía fecha de construcción (Bevià i Garcia, Camarero Casas, 1985).

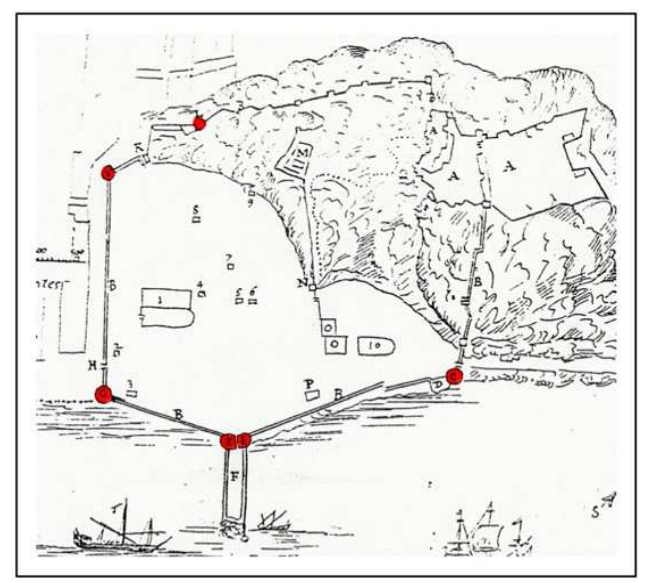

Fig. 1. Alicante en el siglo XVII. De izquierda a derecha: L) Torreón de l'Ampolla (UTM X 719.913 y UTM Y 4.247.395); Y) Torreón de Sant Francesc (UTM X 719.827 y UTM Y 4.247.291); G) Torreón de Sant Bertomeu (UTM X 719.950 y UTM Y 4.247.006); E) Torreones de la Nostra Senyora de Montserrat (UTM X 720.188 y UTM 4.247.044); C) Torreón de Sant Sebastià (UTM X 720.437 y UTM Y 4.247.270) (P. M. Orts i Bosch, 1971).

\section{Los torreones de la muralla}

\subsection{Torreón de Sant Francesc}

También conocido como el torreón de Caputxines, en 1804 tenía las siguientes dimensiones, " 10 varas, 2 pies y 8 pulgadas de diámetro, 2 varas, 8 pies y 6 pulgadas de alto y 3 varas y 6 pulgadas de espesor en su clave" (Mas, 1972, p. 17). Antes de pasar a metros las anteriores medidas, se hace hincapié en una errata de escritura, o transcripción del documento, al asignar una altura de 2 varas $(1,67 \mathrm{~m})$ al interior de la sala. A todas luces dicha altura es imposible. Tomaremos para su representación la altura de 8 varas de la bóveda anexa de la puerta de l'Horta, más el grosos de la bóveda $(6,70+2,73 \mathrm{~m})$ (Ricaud, 1783). El resultado sería $9,10 \mathrm{~m}$ de diámetro interior, $6,70 \mathrm{~m}$ adoptados para la altura de la bóveda y $2,63 \mathrm{~m}$ de grosor en la clave.

A todo ello hay que sumar el resultado de la excavación arqueológica de 1999 que, de nuevo, proporciona datos más precisos sobre el torreón. El mismo tendría "unos $21 \mathrm{~m}$ de diámetro presenta un anillo de macizo de mampostería (6 $\mathrm{m}$ de longitud), que deja en el interior una sala central 
de unos $9 \mathrm{~m}$ de diámetro, sala a la que se accedía por un pequeño pasillo de $1,70 \mathrm{~m}$ de ancho localizado en el centro oriental del torreón". Además, contaba con "un zócalo de $80 \mathrm{~cm}$ a 1,20 m de alzado con un pequeño saliente o moldura algo irregular en su parte superior, zócalo que se apoyaría en el nivel geológico de la zona. A partir de esta base, queda $1,40 \mathrm{~m}$ de torreón, con cierta tendencia ataluzada y que se caracteriza por la mampostería careada y un rejuntado con mortero de cal" (Soler López, et al., 2002, p. 62) (Fig. 3).

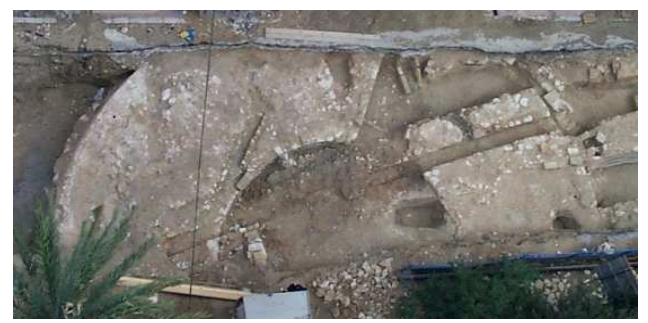

Fig. 3. Vista aérea del torreón de Sant Francesc (L. Soler López, J. R. Ortega Pérez, J. L. Simón García, 2002).

Además, se dispone de un excelente levantamiento de su planta, realizada por el ingeniero B. Ricaud (1783), que refleja fielmente la documentación escrita y arqueológica. No obstante, no se conoce ninguna imagen que defina el alzado del torreón, desaparecido, también, entre 1816 y 1820 , por lo que la reconstrucción gráfica de su alzado se ha realizado por analogía con el torreón de Sant Bertomeu (Fig. 4).

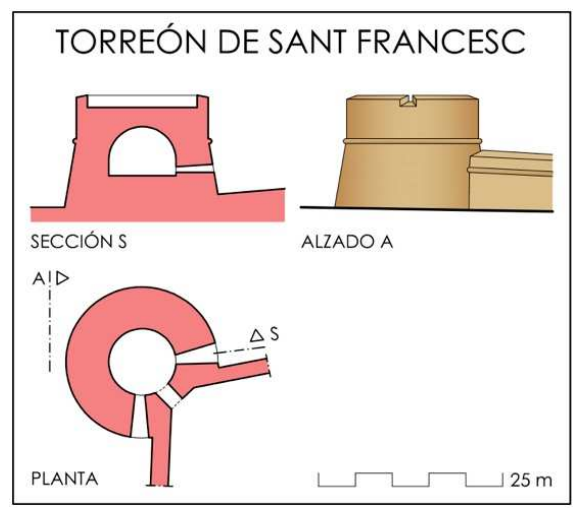

Fig. 4. Propuesta formal de planta, sección y alzado del torreón de Sant Francesc (M. Bevià i Garcia y J. M. Giner Martínez).

\subsection{Torreón de Sant Bertomeu}

El informe completo sobre Alicante del año 1804 (Mas, 1972, p. 17) y, en concreto, en el apartado "En la plaza. Edificios a propósito para almacenes, cuarteles y hospitales"; se indican las características básicas de la construcción "cuya bóveda tiene 14 varas de diámetro, nueve varas y dos pies de altura y dos varas de grueso en su clave". En metros, sus dimensiones serían las siguientes: $11,70 \mathrm{~m}$ de diámetro de la cámara interior, $8,08 \mathrm{~m}$ de altura y 1,67 $\mathrm{m}$ de grosor de la bóveda.Dichas medidas coinciden con las proporcionadas por la excavación desarrollada en el año 1999 (Fig. 5): "La porción de torreón excavado nos ha permitido conocer la dimensión total del mismo, que es de unos $23 \mathrm{~m}$ de diámetro, con un anillo concéntrico de mampostería que deja un espacio central de unos $11 \mathrm{~m}$ de diámetro, cuya base está terraplenada; espacio que ocupa la sala interior del torreón" (Soler López, et al., 2002, p. 66). Además, "presentaba una base o zócalo en moldura de $1,20 \mathrm{~m}$ de altura, a partir de la cual el mismo adquiría su alzado en forma alamborada" (ídem). Respecto su fábrica, se empleó la mampostería unida con mortero de cal.

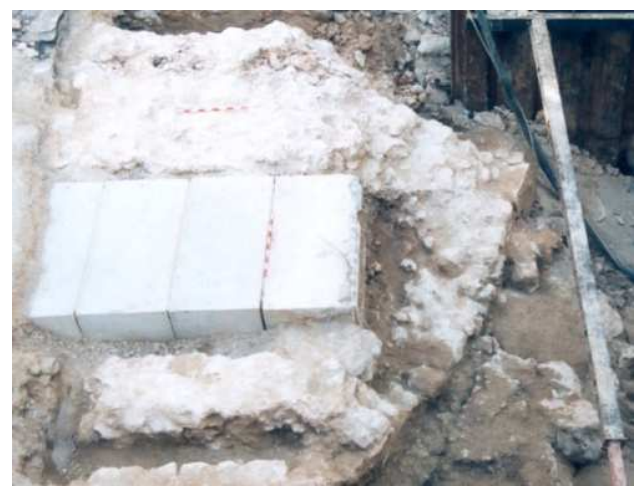

Fig. 5. Vista aérea del torreón de Sant Bertomeu (L. Soler López, J. R. Ortega Pérez, J. L. Simón García, 2002).

Del alzado existen abundantes imágenes más o menos fieles, mereciendo suficiente credibilidad la vista del torreón existente en la estampa "Vue genérale d'Alicante" del libro de viajes de Alexandre de Laborde (Baugean, 1806-1820), que se toma para su representación. Y, aunque no sea muy fiable, el plano y perfil de la "Torre de la puerta de Helche" (Anónimo, 1750), proporciona 
datos acerca de los huecos y la posición de los mismos. Toda esta información se ha empleado para realizar una reconstrucción a nivel de alzado, sección y planta (Fig. 6). Finalmente, el torreón, también, fue derribado, entre los años 1816 y 1820 -al demolerlo junto con el tramo de muralla de El Vall-; para crear, en su solar, el Paseo de la Reina, hoy convertido en la Rambla de Méndez Núñez.

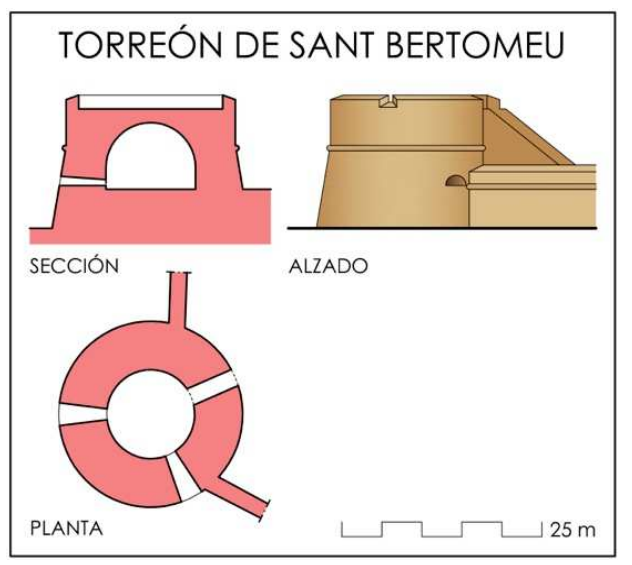

Fig. 6. Propuesta formal de planta, sección y alzado del torreón de Sant Bertomeu (M. Bevià i Garcia y J. M. Giner Martínez).

\subsection{Torreón de Sant Sebastià}

La descripción de 1804 lo explica como una "figura circular, cuya bóveda tiene 9 varas y un pie de diámetro, y 8 varas y un pie de altura con cuatro pies de grueso en su clave" (Mas, 1972, p. 17). Es decir, 7,80 m de diámetro del espacio central, $7 \mathrm{~m}$ de altura y $1,12 \mathrm{~m}$ de grosor de la bóveda. El diámetro total del torreón se conoce por el plano "Proyecto de fortificación" (Climent, 1875). Se trata de un documento grafiado elaborado por la posibilidad de un ataque del ejército carlista a la ciudad, en el que ya no aparecen las defensas del siglo XVI porque han sido derribadas, pero todavía queda en pie el cubo que nos ocupa. A partir de los resultados de la excavación arqueológica realizada en 2010, se puede afirmar que el torreón “(era) una construcción de planta circular cuyo diámetro debe establecerse en torno a $18 \mathrm{~m}$ de base y de unos $16 \mathrm{~m}$ en el estado actual de destrucción" (Borrego Colomer, Rosser Limiñana, 2014, p. 333). Estaba construido por "un paramento de bloques organizados en hiladas que actúa como forro exterior de un relleno constructivo de piedras de tamaño diverso y grandes bloques trabados con un mortero de cal de muy buena calidad y consistencia" (Borrego Colomer, Rosser Limiñana, 2014, p. 333).

Para continuar con la reconstrucción formal de esta obra, se cuenta con la información que proporciona la fotografía de J. Laurent "Vista del muelle. 1858", en la que se ve el frente marítimo de las murallas de la ciudad, los torreones de la Nostra Senyora de Monserrat y de Sant Sebastià, así como el resto de murallas sobre el monte Benacantil y el Castillo de Santa Bárbara (Huguet Chanzá, et al., 2003, pp. 204, 205) (Fig. 7). El torreón pervivió hasta el año 1889, pues todavía aparece dibujado en los dos Anteproyectos de Ensanche de los arquitectos J. González Altés y J. Guardiola Picó (Calduch Cervera, J.; Varela Bote1la, 1979). Posiblemente, su demolición se produciría algunos años después de dicha fecha.

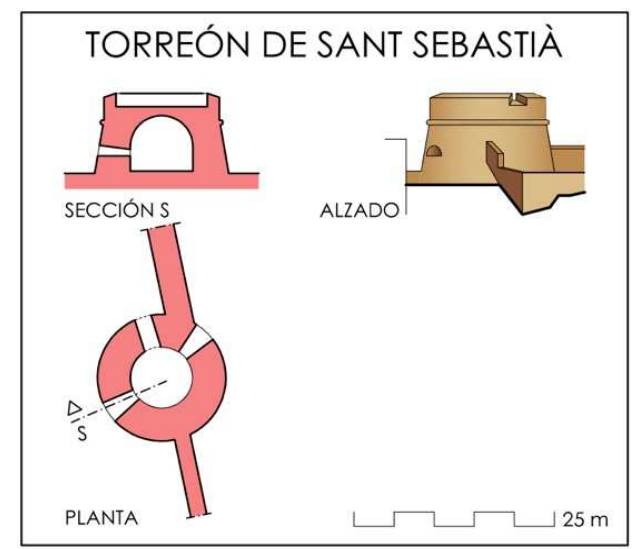

Fig. 7. Propuesta formal de planta, sección y alzado del torreón de Sant Sebastià (M. Bevià i Garcia y J. M. Giner Martínez).

\subsection{Torreones de la Nostra Senyora de Mon- tserrat}

La descripción de 1804, por motivos desconocidos, solo da las medidas de la bóveda de paso, situada entre los dos torreones, y no hace ningún comentario a las salas interiores de éstos. Dicha bóveda "tiene 7 varas y un pie y tres pulgadas de ancho; nueve varas de largo y seis de alto con dos varas y nueve pulgadas en su clave" (Mas, 1972, 
p. 17) que, traducidas a metros, serían las siguientes: $6,20 \times 7,52 \times 5,01 \mathrm{~m}$ y $1,70 \mathrm{~m}$ en la clave. Todas ellas servirán para escalar, posteriormente, los dibujos.

Al estar vinculadas al puerto, existe abundante material gráfico que las representan. Si bien los torreones están repletos de modificaciones en su planta y alzados, por las mejoras continuas y cambios funcionales de las instalaciones que se les iban adosando. Para su reconstrucción formal, se han seguido los planos de E. Panon, de 1749, 1752, 1753, y de J. de la Rocha y Figueroa, de 1792; y la imagen de su alzado "Muelle de Alicante" del pintor M. R. Sánchez (Fig. 8).

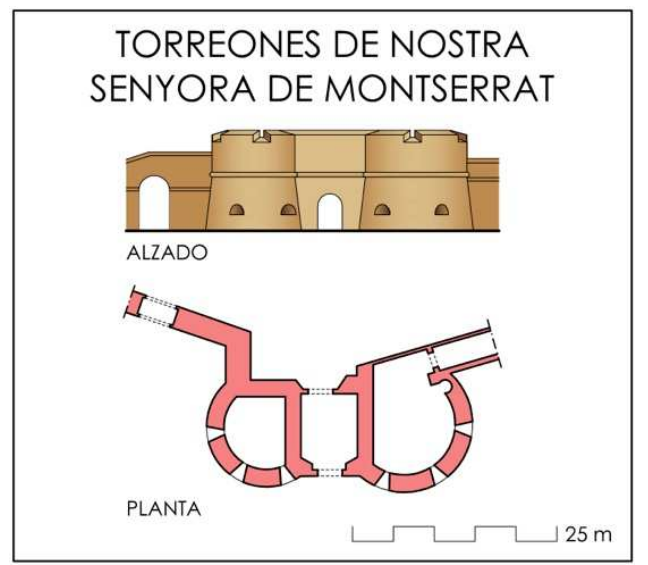

Fig. 8. Propuesta formal de planta y alzado de los torreones de la Nostra Senyora de Montserrat (M. Bevià i Garcia y J. M. Giner Martínez).

Según se aprecia en la fotografía de J. Laurent, todavía se conservaban en pie en 1858 , siendo demolidos en la década siguiente, pues en las fotografías de 1870 ya no aparecen. Las excavaciones arqueológicas del año 2015 aportan algo más de información: "Los restos de la torre documentados corresponderían a parte del torreón occidental de los dos que integraban el complejo de construcciones de la Puerta. Se ha podido exhumar algo menos de la mitad de la planta, que no presenta forma perfectamente circular, sino ligeramente elipsoidal [...]. Se trata de una sólida construcción de mampostería y cal de la que se ha podido documentar los primeros $1,25 \mathrm{~m}$ de profundidad, teniendo en cuenta que solamente se ha procedido a excavar hasta la aparición del nivel freático. La estructura presenta un perfil ligeramente ataludado" (López Seguí, Torregrosa Giménez, 2015, p. 36).

Una vez formalizada la propuesta de alzado de los torreones cabe comentar la escasa pericia de su diseño. Al tratarse de dos torreones que defendían una puerta, la lógica proyectual pide el diseño de una pieza simétrica, y más en ese siglo. En cambio, e hipotéticamente, parece que primero se hubiera ejecutado el torreón de la derecha y al no haber quedado convencidos de la solución realizada se procedió a la construcción del de la izquierda, que es más pequeño, quizás, por la falta de espacio. Todo ello, se realizó con urgencia y poca experiencia, de manera que incluso el cuerpo central que aloja la puerta también resulta asimétrico. La propuesta de J. B. Calvi debió parecer muy cara y complicada a los jurados alicantinos $\mathrm{y}$, por ello, optaron por una solución doméstica, copiando soluciones ya existentes en la muralla, y con artífices locales poco experimentados (Bevià y Camarero, 1985, p. 203).

\subsection{Torre de l'Ampolla}

A pesar de su tardía cronología, puede adscribirse a esta arquitectura, todavía hoy en pie. A finales de 1596 el Marqués de Dénia, virrey del Reino de Valencia, recibió una carta en la que "Los justicias y jurados de la Ciudad de Alicante me han enviado dos trazas de un Baluarte que determinan hacer en aquella ciudad cabe el portal de la huerta y juntamente con ellas el parecer de Cristóbal Antonelli ingeniero de vuestra Magestad y de Juan Torres Cantero que hizo el pantano [...]" (Bevià i Garcia, M.; Camarero Casas, 1985, p. 216). Debió construirse por estas fechas, siendo uno de los torreones que definían la defensa de la ciudad, pues en 1640 el cronista V. Bendicho (Cabanes, 1991, p. 92) lo nombra al mismo nivel que el resto de torreones anteriores.

Presenta una tipología semejante a los descritos con anterioridad: circular alamborada con media caña de sillería en el encuentro vertical y sala interior rodeada de gruesos muros. En 1804 se describe "más arriba de la batería de San Antón [...] tiene 2 varas de diámetro [...], 9 de altura con dos pisos intermedios y 7 pies de rosca en la bóveda" (Mas, 1972, p. 18). 
En la actualidad sirve de mirador, las salas interiores están terraplenadas y no se ha realizado excavación arqueológica alguna que nos permita tener más conocimiento sobre esta pieza (Fig. 9).

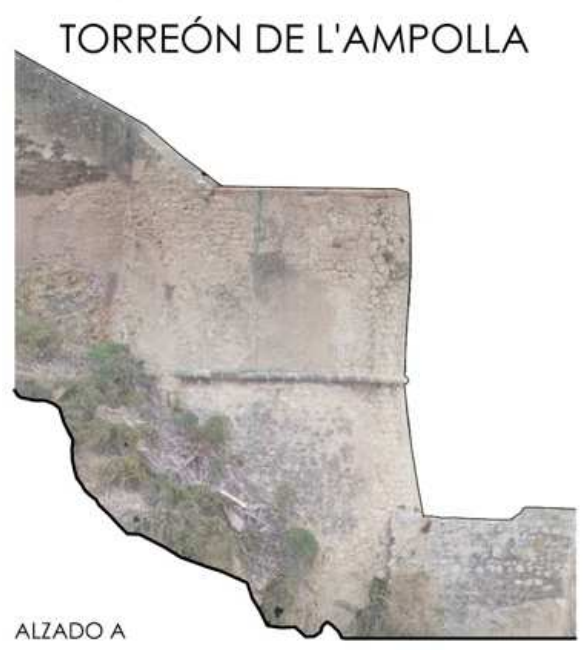

Fig. 9. Alzado de la torre de 1'Ampolla (M. Bevià i Garcia y J. M. Giner Martínez).

\section{Conclusiones}

Para concluir, cabe señalar que las fortificaciones realizadas en Alicante, a partir de 1533 y a lo largo del siglo XVI, se enmarcan dentro de las soluciones generalizadas para la defensa de las plazas con existencia de un amurallamiento medieval potente y con necesidad de incorporar piezas de artillería para aumentar la capacidad de resguardo para una ciudad de la importancia estratégica y económica como Alicante, en el ámbito del Reino de Valencia.

Como recoge R. Martí de Viciana (1564) “[...] la fortificación de la tierra en la cual de doce años a esta parte han gastado en el muro que hicieron a la mar, y baluartes más de cincuenta mil ducados que esto ha sido la redención de la tierra. De esta fortificación resultan dos comodidades a la ciudad: la una es amparo y seguridad de las personas y haciendas propias y la otra acrecentamiento de casas para los moradores; [...] los mercaderes que tenían contratación en Cartagena se ha mudado a esta ciudad; porque las boticas de sus mercaderías están muy seguras dentro del fuerte muro y los navíos en la mar, por los buenos asideros; están seguros de tormenta; y aun de corsarios; porque la artillería de los baluartes son ayudados y defendidos" (Martínez, 1971, pp. 37 y 38).

Joan de Cervelló, junto con Pedro de Castroverde -hombre de confianza del duque de Calabria, virrey del Reino de Valencia, en su visita a Alicante, en 1533, por orden del virrey-; se preocupó de mejorar las viejas murallas existentes diseñando cubos artillados en los ángulos principales del recinto, capaces de albergar piezas de artillería diversa (culebrinas, medias culebrinas, sacres, falconetes, medios falcones y tercios y cuartos de cañón).

En este sentido, se construyeron los torreones de Sant Francesc, Sant Bertomeu y Sant Sebastià. Como prueba de ello las armas del emperador estaban "[...] sobre la puerta delche, en los baluartes del portal nuevo, en el de la puerta de guerta y en el del portal delche donde en los baluartes están las del duque de Calabria [...]" (Bendicho, 1653 , s.p). Y, además, en 1535, se colocaron dos lápidas presidiendo los torreones de Sant Bertomeu y Sant Sebastià, de la forma que sigue (Cabanes Catalá, 1991, pp. 778, 779): "DE. MAN. EX. DVCIS. CALABRIA // LOCVM TEN. GENE. S. C. M. // CAROLI REGIS. ET. DOMINI. NOST. // INVENTOR. ERIT. JOANE SERVE. // LLO. PROSECVTOR. PETRUS. DE. // CASTRO. VERDE. DOMESTICUS. // PREDICTI DVCIS. CALABRIE // MAGISTER. JOANNES. RIERA // FVIT. PER. ANNO M. D. XXXV // JURATI. MICAEL VENRELL. CE // SAR. GVILL. DOMICELLI. PETRI // SCEVA MILITI $/ . "$

Estas mejoras finalizaron, en la segunda mitad del siglo XVI, con la construcción torre de l'Ampolla y de los torreones de la Nostra Senyora de Montserrat, que estarían finalizados en 1564, pues aparecen frente al muelle en el grabado de Alicante de la crónica de R. Martí de Viciana de ese año (Martínez, 1971, p. 21).

Todos ellos presentaban planta circular con la finalidad de no tener puntos débiles, como las esquinas, evitar impactos frontales y facilitar los rebotes de los proyectiles. Estas defensas tenían los muros muy gruesos, alamborados en parte de su alzado, protegiendo salas abovedadas para la ins- 
talación de artillería y con una altura reducida para minorar la posibilidad de los impactos, en nuestro caso en una relación cuatro partes de base por tres de altura como hemos mostrado en paginas anteriores. Otra característica era la de plantear dos niveles de tiro, el de la cubierta desde donde se podía cubrir el territorio circundante y el de la de nave interior para barrer en rasante lateral los lienzos de muralla y las puertas colindantes.

Esta utilización "económica" de la modernización y mejora de las plazas se generalizó hasta bien avanzado el siglo XVI a lo largo y ancho del Mediterráneo, cuando la arquitectura abaluartada ya estaba consolidada. En el Reino de Valencia existen diversos ejemplos: Calp, Castalla, Dénia, Gandia, Oliva, València, etc. No obstante, la misma fue muy denostada por los ingenieros italianos caso de, por ejemplo, J. B. Antonelli y V. Gonzaga (Bevià i Garcia, Camarero Casas, 1985, pp. 204 y 215); que tomaron el relevo a los primeros militares y artilleros experimentados, "inventors" como Cervelló, en las inspecciones de la defensa de la costa del reino, proponiendo obras ideales de nueva planta, con altísimos costos económicos y consiguiente ruina para los contribuyentes. Calificando estas arquitecturas defensivas de transición como de "lanza y escudo" y por tanto inservibles.

Por otro lado, el levantamiento gráfico realizado demuestra que los tres cubos responden a un mismo criterio formal y compositivo, sin ser iguales de tamaño (Fig. 10). Ello prueba que se deben a una misma mano proyectual. Así vemos que el torreón de Sant Bertomeu es el más grande, ocupa la posición estratégica de mayor riesgo, la esquina de la muralla frente al mar y el Vall, defendiendo la principal puerta de tierra; que el cubo de Sant Sebastià es el más pequeño y se asienta en la punta rocosa de l'Esperó sin mucho espacio para desarrollarse; y que el de Sant Francesc se ejecuta en un tamaño intermedio, atendiendo al papel secundario que ocupa en la muralla. Pero todos responden al mismo criterio compositivo: planta circular de cuatro partes o módulos de diámetro, ocupando la sala central dos módulos y el grosor de los muros otro módulo. La altura se resuelve en todos ellos elevando tres partes del diámetro de su planta, resultando unos torreones de poca altura, de aspecto macizo y poco expuestos a los tiros de la artillería.

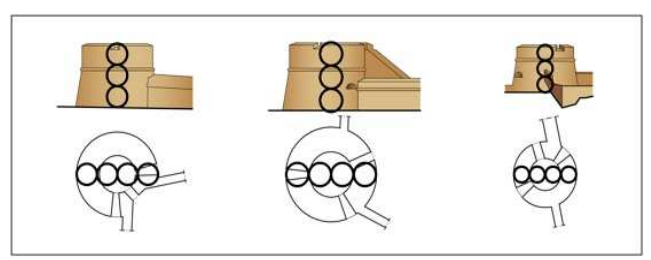

Fig. 10. Modulación de los torreones de Sant Francesc, San Bertomeu y Sant Sebastià (M. Bevià i Garcia y J. M. Giner Martínez).

\section{Bibliography}

A.A. (1751). Plano y perfil de la Torre de Ramiro, Archivo General de Simancas, Colección de Mapas, Planos y Dibujos, Signatura MPD, 65, 091.

Baugean, J.J. (1806-1820). "Vue genérale d'Alicante", in Voyage pittoresque et historique de l'Espagne, Paris Ed.

Bendicho, J. (1653). Fragmentos nuevos de los Linages viejos y nuevos de la ciudad de Alicante, (inédito), p. 360.

Cabanes Catalá, Mª L $^{\mathrm{a}}$. (1991). Chronica de la Muy Ilustre, Noble y Leal Ciudad de Alicante, Ayuntamiento de Alicante Ed., Alicante, p. 1040.

Bevià i Garcia, M.; Camarero Casas, E. (1985). Arquitectura Militar Renacentista en la costa alicantina (siglo XVI). Proyectos y obras mayores, (inédito), p. 690.

Bevià i Garcia, M.; Mira Rico, J.A.; Ortega Pérez, J.R.; Baldaquí Escandell, V.R.; Yáñez Martínez, Mª.B. (2017). "La Torre Grossa del Castell de Castalla (Alicante, España). Un ejemplo primerizode arquitectura preabaluartada en el sur del Reino de Valencia", in FORTMED 2017. Defensive Architecture of the Mediterranean XV to XVIII Centuries, vol. 6, pp. 107-114.

Borrego Colomer, M.; Rosser Limiñana, P. (2014). "Calles Villavieja, 30 y Paseo Ramiro 13: el Torreón de San Sebastián y la Torre del Speró (Casco Antiguo de Alicante)", in Arqueología en Alicante en la primera década del siglo XXI, pp. 331-337. 
Calduch Cervera, J.; Varela Botella, S. (1979). Guía de arquitectura de Alacant, Colegio de Arquitectos de Alicante Ed., Alicante, p. 164.

Climent y Martínez, V. (1875). Proyecto de fortificación formado en el supuesto de guerra civil, Servicio Histórico Militar-España, Plano n 2577, Signatura B-2-9, $\mathrm{N}^{\circ}$ de hojas 8, Hoja 2.

García Martínez, S. (1980). Bandolers, corsaris i moriscos, Tres i Quatre Ed., València.

González Avilés, A.B. (2012). "Los inicios de la fortificación abaluartada en Alicante, la muralla de Carlos V”, in Actas del IV Congreso de Castellología, Asociación Española de Amigos de los Castillos Ed., Madrid, pp. 787800.

Huguet Chanzá, J., et al. (2003). Las fotografías valencianas de J. Laurent, Ajuntament de València Ed., València, p. 271.

Ivars Pérez, J. (2015). Dénia. La Ciutat i el Castell. L'arquitectura militar baluartada (segles XVI-XIX), Ajuntament de Dénia y Universitat de València Ed., Valencia, p. 336.

López Seguí, F.; Torregrosa Giménez, P. (2015). Intervención arqueológica realizada en la Explanada de España. Fase I. Tramo entre Rambla y Puerta de la Mar (Alicante), (inédito), p. 46.

Martínez Morellá, V. (1971). Alicante en la "Chronica de la Ínclita y Coronada Ciudad de Valencia y su Reino" de Martin de Viciana, Ayuntamiento de Alicante Ed., Alicante, p. 41.

Más y Gil, L. (1972). Informe Incompleto sobre Alicante. Año 1804. Transcripción, notas y comentarios, Ayuntamiento de Alicante Ed., Alicante, p. 50.

Orts i Bosch, P.Ma . (1971). Alicante. Notas históricas (1373-1800), Edición propia Ed., Valencia, p. 177.

Panon, E. (1749). Plano del muelle actual del puerto de Alicante, Archivo General de Simancas, Colección de mapas, Planos y Dibujos, Signatura MPD, 30, 003.

Panon, E. (1752). Porción de la puerta y muelle de Alicante, Archivo General de Simancas, Colección de mapas, Planos y Dibujos, Signatura MPD, 06, 163.

Panon, E. (1753). Plano, perfil y elevación de una casa de aduana proyectada en la plaza de Alicante, Archivo General de Simancas, Colección de mapas, Planos y Dibujos, Signatura MPD, 22, 054.

Pardo Molero, J.F. (2006). "Cultura de la guerra y cultura de la defensa en la Europa del Renacimiento: Juan de Cervelló (1496-1551)”, Manuscrits: Revista d'història moderna, 24, pp. 19-43.

Ricaud, B. (1783). Plano de una porción del Recinto de la Plaza de Alicante, Archivo General de Simancas. Colección de Mapas, Planos y Dibujos, Signatura MPD, 06, 153.

Rocha y Figueroa, J. De. (1792). Plano que manifiesta el nuevo tinglado construido para la pescadería, Archivo General de Simancas, Colección de Mapas, Planos y Dibujos, Signatura MPD, 04, 142.

Sánchez, M.R. (1781-1803). "Vista del muelle de Alicante", in Museo del Prado, No de Catálogo: P 003990.

Soler López, L.; Ortega Pérez, J.R.; Simón García, J.L. (2002). "Excavaciones arqueológicas de salvamiento en la Rambla (Alicante). Avance de los resultados", Castells, 8, pp. 59-68. 